\section{Los síntomas melancólicos del filósofo en las Intercenales (1424-1439) de Leon Battista Alberti}

\author{
MARIO PRADES ${ }^{1, \mathrm{a}}$
}

\section{The melancholy of the philosopher in the Intercenales (1424-1439)}

This essay analyzes the presence of the modern concept of melancholy in the Intercenales (1424-1439) by the humanist Leon Battista Alberti. The Intercenales is a collection of satirical, allegorical and moralizing writings composed with the purpose of entertaining an audience of close friends. In spite of the fact that the term "melancholia" does not appear in the text, this paper argues that Alberti's character of "the philosopher" is melancholic, since he is "ill in the soul" (suffering from morbus animi), and his illness is evidenced by a series of physical and psychological symptoms associated with melancholy in the classical and medieval medical traditions. These symptoms are stomach pain, pallor, insomnia, a rich memory, a propensity to study at night, and an ability to have premonitory dreams. With this characterization Alberti promotes a connection between melancholy and being a genius, which is distinctive to the Renaissance and the basis for the modern concept of melancholy. The essay concludes that the ultimate purpose of the Intercenales is to cure, from a literary and philosophical point of view, the illness of the melancholic philosopher.

(Rev Med Chile 2019; 147: 1053-1058)

Key words: Depressive Disorder; History of Medicine; Literature; Philosophy.

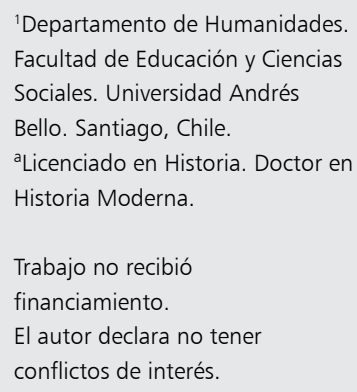

Recibido el 15 de marzo de 2019, aceptado el 28 de agosto de 2019.

Correspondencia a:

Mario Prades

Sazié, $2325,2^{\circ}$ piso, Santiago, Chile.

mario.prades@unab.cl
E ste ensayo se propone analizar la presencia del moderno concepto de melancolía en algunas Intercenales de Leon Battista Alberti (1404-1472), a pesar de que dicho término no figura en ellas de manera explícita. Sin embargo, se pude calificar de melancólico un personaje-tipo muy característico: el del filósofo "enfermo en el alma", cuya enfermedad se expresa tanto a través de síntomas físicos (palidez, mal de estómago) como psíquicos (sueños reveladores, propensión a estudiar durante la noche, gran capacidad mnemónica), tradicionalmente atribuidos a los melancólicos por la literatura médica antigua y medieval. Esta asociación entre filosofía y melancolía resulta clave para entender el carácter "curativo" que la obra se atribuye.

\section{El autor y la obra}

Leon Battista Alberti es uno de los autores más emblemáticos del Renacimiento florentino durante el siglo XV. Fue arquitecto, tratadista, matemático, filósofo, músico y poeta, componiendo así el ideal de humanista propio de la época. Las Intercenales (también conocidas como Intercoenales o Intercenali en italiano) fueron compuestas entre 1424 y 1439 para un público bien restringido. La obra consiste en una serie de relatos satíricos, alegóricos y moralizantes, distribuidos en varios libros para ser leídos inter coenas et pocula: "entre viandas y néctares". Se inspira, de este modo, en la tradición filosófica helenística, en la que predominan autores como Luciano, Terencio, Plauto 
o Esopo ${ }^{1}$. La influencia lucianesca se advierte en el retrato amargo y pesimista que el autor traza del ser humano, destinado a la infelicidad por culpa del desenfreno de sus deseos y esperanzas. Es común en muchas de las Intercenales que un personaje, encarnación de un filósofo o literato, emita este tipo de juicios, pues el hombre de letras -personificación del mismo Alberti-, en la medida en que aspira a la sabiduría y la virtud, advierte de forma más lúcida la intrínseca precariedad moral de la condición humana. Esta lucidez es una fuente de tristeza que se caracteriza en ocasiones en términos patológicos, tema central de este ensayo.

\section{La enfermedad del filósofo}

El pesimismo del personaje albertiano del filósofo enfermo se debe, en parte, a sus propias vicisitudes personales -en las cuales se refleja la biografía del mismo Alberti--. Tanto en Pupilus como en Erumna el personaje de Filoponio reprocha a la diosa Fortuna ${ }^{2}$ la pobreza y el abandonado familiar resultado de su dedicación a los "nobles estudios". En Defunctus, Neofrono concluye que "debemos considerar afortunados a los que fenecieron antes de encontrar el mal de vivir al borde de la existencia, en el mismo instante en el que llegaron a la luz"4.

Este pesimismo cósmico no solo provoca amargura y tristeza: Alberti en varias ocasiones se refiere a sus males en términos patológicos. Así, por ejemplo, en la ya citada Erumna, tanto Filoponio como su interlocutor se refieren a su tristeza con términos como aegritudo o morbus ${ }^{5}$, traducidos al italiano como "debilidad moral", "malestar", "depresión", "aflicción" o "enfermedad". Alberti también habla de morbus animi, traducible como "enfermedad del alma" -entendida esta en un sentido no cristiano-, o "de la mente". Así, en el proemio al primer libro de las Intercenales, dedicado al médico y astrónomo Paolo dal Pozzo Toscanelli, Alberti declara la finalidad de su obra de este modo:

"Tú, queridísimo Paolo, curas cuerpos enfermos como hacen todos los demás médicos, con medicinas amargas que provocan también disgusto, pero yo, con mis escritos, proporciono un modo para aliviar las enfermedades de la mente [morbus animi], que produce risa y alegría"6.

El personaje albertiano del literato que pade- ce este morbus animi presenta toda una serie de síntomas que corresponden al cuadro médico del melancólico, tal como lo había elaborado la tradición clásica y medieval -el mismo término solía utilizarse para designar dicha enfermedad ${ }^{7}$. Sin embargo, al unir estudio de las letras y melancolía, Alberti reelabora el concepto de melancolía según la caracterización propia del Renacimiento. Como es sabido, durante el siglo XV los humanistas redescubren el Problema XXX, atribuido a Aristóteles, en el cual se atribuye al genio un humor melancólico. Desde este momento, la melancolía se considerará un atributo propio de personas intelectualmente dotadas, y dejará de entenderse como una enfermedad para considerarse un estado de ánimo, producido precisamente por esa inclinación al estudio ${ }^{8}$. A partir de esta característica los humanistas acuñarán el moderno concepto de melancolía?.

Alberti utiliza síntomas propios de la tradición melancólica clásica y medieval para caracterizar a su filósofo pesimista. Esto no significa que las Intercenales sean una obra de medicina o dietética, sino más bien un artefacto literario que se sirve de dicha tradición médica con un propósito filosófico. Repasaremos, por tanto, estos síntomas, para señalar en la conclusión el significado general de la melancolía albertiana.

\section{Síntomas físicos de la melancolía}

Los síntomas físicos melancólicos del sabio enfermo albertiano son dos: palidez y dolor de estómago. Así, en Religio el personaje de Libripeta reprocha a Lepido: "si no hubieses arruinado tu salud con las largas noches en vela transcurridas leyendo, Lepido, no estarías tan pálido ni enfermo del estómago" ${ }^{10}$. En Patientia la diosa Necesidad describe al estudioso como "pálido y débil"11. La palidez y el dolor de estómago constituyen síntomas tradicionalmente atribuidos a la melancolía por la doctrina de los cuatro temperamentos. Así, el mismo Avicena, en su Liber canonis, enumera tanto la delgadez como la ausencia de color entre los síntomas de quien sufre exceso de bilis negra, causante del humor melancólico ${ }^{12}$.

Alberti conocía bien estos síntomas: el mismo nombre del protagonista de Deifira, Pallimacro, alude a los dos síntomas asociados por Avicena a los melancólicos: palidez (palitas) y delgadez 
Tabla 1. Síntomas melancólicos en las Intercenales y fuentes médicas asociadas

\begin{tabular}{|c|c|c|c|}
\hline Síntoma & $\begin{array}{l}\text { Intercenal donde } \\
\text { aparece }\end{array}$ & Personaje paciente & $\begin{array}{l}\text { Fuente médica que lo asocia a la } \\
\text { melancolía }\end{array}$ \\
\hline Palidez & $\begin{array}{l}\text { Religio } \\
\text { Patientia }\end{array}$ & $\begin{array}{l}\text { Lépido } \\
\text { Los estudiosos }\end{array}$ & $\begin{array}{l}\text { - Avicena. Liber canonis } \\
\text { - Marsilio Ficino. De vita }\end{array}$ \\
\hline Dolor de estómago & Religio & Lépido & $\begin{array}{l}\text { - Avicena. Liber canonis } \\
\text { - Marsilio Ficino. De vita }\end{array}$ \\
\hline Insomnio & $\begin{array}{l}\text { Oraculum } \\
\text { Scriptor } \\
\text { Fatum et fortuna }\end{array}$ & $\begin{array}{l}\text { Libripeta } \\
\text { Lépido } \\
\text { Anónimo }\end{array}$ & $\begin{array}{l}\text { - Regimen Sanitatis Salerni } \\
\text { - Constantino Africano. De Melancholia }\end{array}$ \\
\hline Memoria y fantasía & $\begin{array}{l}\text { Pupilus } \\
\text { Erumna }\end{array}$ & $\begin{array}{l}\text { Filoponio } \\
\text { Filoponio }\end{array}$ & $\begin{array}{l}\text { - Aristóteles. Sobre la memoria y la reminiscencia } \\
\text { - Aristóteles. Ética nicomáquea } \\
\text { - Alexander Neckam. De naturis rerum libri duo }\end{array}$ \\
\hline Sueños reveladores & Fatum et fortuna & Anónimo & $\begin{array}{l}\text { - Platón. Timeo } \\
\text { - Aristóteles. Ética eudemia } \\
\text { - Aristóteles. Parva naturalia } \\
\text { - Escuela hipocrática. Sobre la dieta }\end{array}$ \\
\hline
\end{tabular}

(macer), aplicados aquí a un tipo muy preciso de melancólico: el que sufre mal de amores (distinto del enfermo por el exceso de estudio, que nos ocupa $)^{13}$. En la Florencia de la época, ambos síntomas se asocian al trabajo intelectual de los humanistas. Lo vemos, por ejemplo, en el primer libro De vita (1480-1489) de Marsilio Ficino, dedicado expresamente a la salud de los estudiosos de las letras. En ella el médico y filósofo florentino explica el dolor de estómago por la incompatibilidad entre el proceso fisiológico de la digestión y la actividad intelectual, pues "en ese momento para digerir la comida el estómago necesita más espíritus y mucho calor. Unos y otros, en cambio, son desviados y dirigidos a la cabeza por el desvelo y el estudio". De este modo la comida, abandonada por el calor y los espíritus de la sangre, no se digiere sino que se pudre ${ }^{14}$, causando dolor de estómago. Por este motivo, Ficino desaconseja al humanista estudiar después de las comidas y, especialmente, durante la noche. Este debe, por contra, acostarse pronto y aprovechar las primeras horas de la mañana para el estudio, pues con ello se expone a los rayos más benéficos del sol y sincroniza su actividad con la de los astros. No hacerlo causa palidez, dolor de estómago y, en última instancia, melancolía.

\section{Predisposiciones del animus}

Con este término entendemos las características que no corresponden a síntomas específi- camente físicos. Abordaremos tres: la tendencia a velar durante la noche, la exacerbación de la fantasía y la memoria, y la capacidad de tener sueños premonitorios.

En las Intercenales estudiar supone trasnochar. En Oraculum el oráculo responde a Libripeta que logrará ser un hombre de letras leyendo "día y noche" 15 . En Scriptor, de nuevo Libripeta reprende al estudioso Lepido: "idisipador de tu propio trabajo! Pienso que harías mejor durmiendo que malgastando tus vigilias con el estudio" 16 . Por su parte, el filósofo anónimo que protagoniza Fatum et fortuna tiene un sueño revelador después de "haber velado mucho durante la noche, leyendo todo lo que nos han legado los antiguos sobre el destino"17.

Ahora bien, el insomnio constituye una de las características que la literatura médica atribuye tradicionalmente al melancólico. Un ejemplo de esto lo encontramos en el Regimen Sanitatis Salernitanum, cuyo capítulo 89 concede al melancólico dos características positivas: "permanecen vigilantes en el estudio, ni su mente se abandona al sueño" ${ }^{18}$. Se trata de la primera mención, desde Aristóteles, de la dedicación melancólica al estudio, pero no del insomnio, pues ya Constantino Africano sostenía que la bilis negra combusta (causante de la melancolía) produce insomnio ${ }^{19}$. Será en el Renacimiento cuando, por primera vez, el insomnio será causa de la melancolía y no solo síntoma, distinguiéndose así entre una melancolía "natural" (humoral) y una adquirida 
por la dedicación nocturna al estudio -lo vemos, por ejemplo, en Ficino-. Así, el carácter insomne del sabio albertiano remite claramente a la figura del melancólico según la tradición temperamental clásica.

Por su parte, la exacerbación de la fantasía y la memoria está tradicionalmente relacionada con el humor melancólico. Ya Aristóteles, en su tratado Sobre la memoria y la reminiscencia, observaba que las imágenes del pasado (phantasmata) golpean con mayor fuerza y se afianzan con más vigor en el carácter del melancólico, debido a su especial sensibilidad imaginativa ${ }^{20}$. De todas las cualidades positivas que el estagirita atribuye al melancólico, esta será, junto a la astucia, la única que perdurará durante la Edad Media cristiana, gracias en parte la obra de Alekander Neckam ${ }^{21}$.

¿Tiene el filósofo albertiano buena memoria? Sí, si por tal entendemos la capacidad para revivir hechos del pasado con extrema viveza. Por ejemplo, tanto en Pupilus como en Erumna el personaje de Filoponio evoca todas las vicisitudes que lo han convertido en un hombre desgraciado: la muerte del padre, las luchas familiares, la deshonra, los impedimentos para el estudio, la pérdida de su herencia, etc. A partir de estos recuerdos Filoponio se ve empujado a una amarga visión de la naturaleza humana. Su memoria es, en ambas piezas, la causa de su frustración y decepción. Ahora bien, esta capacidad mnemónica no se despliega tanto en la precisión del recuerdo cuanto en su capacidad evocativa de estados de ánimo, penas y sufrimientos. En este sentido, la memoria profundamente emotiva de Filoponio se encuentra íntimamente asociada a su morbus animi.

Esta característica puede relacionarse con la psicología aristotélica, que explica la memoria a partir de la teoría de los cuatro humores. Para Aristóteles la buena memoria se debe al movimiento humoral, pues "el humor, una vez en movimiento, no se detiene hasta que el objeto que se buscaba [el phantasmata] vuelva a la mente y el movimiento encuentre la recta vía". Este movimiento podría revelarse en forma de emociones provocadas por imágenes revividas en la memoria, es decir, "imaginadas". Precisamente la melancolía se define tradicionalmente como una alteración de la vis immaginativa, es decir, de la función racional capaz de producir imágenes como las que Filoponio revive (ya en la Ética nicomáquea encontramos una relación sustancial entre melancolía e imagina- ción $)^{22}$. Por ello creemos, de manera conjetural, que el tipo de memoria del que habla Aristóteles podría de nuevo asociar al sabio albertiano con el cuadro médico del melancólico.

Por último, queda revisar la capacidad de tener sueños premonitorios. Las narraciones oníricas de las Intercenales describen tránsitos hacia paisajes fantásticos y alegóricos, de los cuales el soñador extrae un aprendizaje moral y filosófico. Lo vemos en Fatum et fortuna, cuyo anónimo protagonista viaja en sueños a la tierra de las almas por nacer. En la representación albertiana de su nacimiento, las almas caen en el río de la vida, donde deberán buscar asideros que les permitan surcarlo. De la fortuna dependerá que naveguen en una cómoda embarcación, en una precaria balsa o que se ahoguen apenas nacidas. De este modo, la imagen alegórica conduce, a través de la fantasía, a la revelación de una verdad fundamental: nuestra dependencia de la fortuna. Así se lo dice al filósofo soñador su también anónimo interlocutor: "Quisiera que contases esa magnífica enseñanza sobre el destino y la fortuna que, decías, te había sido comunicada en sueños. (...) Sobre una cuestión tan intricada has aprendido más tú, durmiendo, que todos nosotros despiertos"23.

En la Ética eudemia Aristóteles se pregunta por qué los melancólicos tienen éxito sin estar bien dotados de razón. Se lo explica aduciendo que su ánima está guiada por un principio más potente que el intelecto, de origen divino, "ya que la divinidad ve bien el futuro y el presente y aquellas cosas de las que la razón se ha separado. Por este motivo, los melancólicos tienen incluso sueños verídicos". Posteriormente, en los Parva naturalia Aristóteles se mostrará escéptico sobre la veracidad de este tipo de sueños y los reconducirá a causas exclusivamente naturales. Aun así, continuará atribuyéndolos a los melancólicos, a quienes concederá por ello el poder "daemonico", esto es, raro o excepcional, de tener sueños verdaderos ${ }^{24}$.

Contemporáneo de Aristóteles, el tratado Sobre la dieta de la colección hipocrática afirma, en su introducción al cuarto libro, que el alma permanece en vela cuando el cuerpo duerme. Puede, así, ser depositaria de sueños provocados por la divinidad, "que preanuncian a ciudades o a privados males o bienes", de los cuales "hay intérpretes con el arte de explicarlos" 25 .

En las Intercenales, la función reveladora del sueño remite a este trasfondo médico-filosófico. 
De este modo, tanto la capacidad de tener sueños reveladores como la fantasía, la memoria y las largas noches en vela colocan al docto albertiano dentro de la caracterización de la melancolía propia de la tradición médica y psicológica.

\section{Conclusión: el significado de la melancolía albertiana}

Vemos, pues, cómo tanto los síntomas psicológicos como los físicos conectan a un personaje típico de las Intercenales con la caracterización del melancólico propia de la tradición médica clásico-medieval. Si bien Alberti no tilda a su personaje de melancólico, conocía esta tradición $\mathrm{y}$, seguramente, era bien consciente de las resonancias que estos episodios tendrían en la mente de sus lectores.

Una vez constatada esta filiación, cabe preguntarse qué pretende nuestro autor con esta caracterización. Como respuesta tentativa, proponemos interpretar las Intercenales como una obra de dietética moral, en la cual elementos como los sueños, el insomnio, la fantasía y la memoria pueden leerse al mismo tiempo como síntomas médicos y atribuciones literarias que tienen una función precisa, no solo estilística sino también filosófica, en la medida en que ilustran una vía de acceso distinta a la verdad: no a través de un razonamiento lógico, sino de imágenes, metáforas y relatos que impresionan tanto la mente como los sentidos. La impresión que el docto albertiano recibe es, en primera instancia, negativa: las visiones oníricas, el recuerdo, las lecturas realizadas durante la noche no hacen sino aumentar su pesimismo existencial. Una vez constatada esta primera impresión y caracterizado el sabio dentro del cuadro melancólico, la tarea de Alberti consistirá en "curar" su melancolía o, por lo menos, consolarlo. Lo hará, de nuevo, a través de la imagen y la alegoría, siguiendo, así, el precepto con el que abría su obra: proporcionar " $u n$ modo para aliviar las enfermedades de la mente, que produce risa y alegría". Tras el diagnóstico, llega el momento de la cura ${ }^{26}$.

\section{Referencias}

1. Bacchelli F, D'Ascia L. 'Delusione' e 'Invenzione' nelle 'Intercenali' di Leon Battista Alberti, en Alberti, LB. Intercenales, ed. a cargo de Franco Bacchelli y Luca
D’Ascia. Bolonia: Pendragon; 2003. La obra no ha sido traducida al español, por lo que utilizaremos traducciones propias.

2. Alberti LB. Intercenali inedite. Edición de Eugenio Garin. Florencia: Sansoni; 1965, p. 48.

3. Alberti LB. Opera inedita et pauca separatim impressa. Hyeronimo Mancini curante. Florencia: Sansoni; 1890, p. 126.

4. Alberti LB. Intercenales, ed. a cargo de Franco Bacchelli y Luca D’Ascia. Bolonia: Pendragon; 2003, pp. 426-31.

5. Alberti LB. Intercenali inedite. Edición de Eugenio Garin. Florencia: Sansoni; 1965, pp. 45-6.

6. Alberti LB. Intercenali inedite. Edición de Eugenio Garin. Florencia: Sansoni; 1965, p. 122.

7. Africano C. Constantini Africani Opera, vol. I. Basilea: Henricum Petrum; 1536, p. 283 y siguientes.

8. Aristóteles. El hombre de genio y la melancolía. Problema XXX. Barcelona: Quaderns Crema; 1996.

9. Klibansky R, Panfosky E, Saxl F. Saturno y la Melancolía. Madrid: Alianza Forma; 2004.

10. Alberti LB. Opera inedita et pauca separatim impressa. Hyeronimo Mancini curante. Florencia: Sansoni; 1890, p. 130.

11. Alberti LB. Opera inedita et pauca separatim impressa. Hyeronimo Mancini curante. Florencia: Sansoni; 1890, p. 147.

12. Avicena. Liber canonis. Venecia: Apud Iuntas; 1555, I, 2, 3, 3-7, ff. 41r-43r.

13. Rinaldi R. Melancholia albertiana: dalla 'Deifira' al 'Naufragus', Lettere italiane 1985; 37: 41-82.

14. Ficino, M. De vita libri tres, Hildesheim-Nueva York: Georg Olms Verlag; 1978, I, 7, cii.

15. Alberti LB. Opera inedita et pauca separatim impressa. Hyeronimo Mancini curante. Florencia: Sansoni; 1890, p. 152.

16. Alberti LB. Opera inedita et pauca separatim impressa. Hyeronimo Mancini curante. Florencia: Sansoni; 1890, p. 125.

17. Alberti LB. Opera inedita et pauca separatim impressa. Hyeronimo Mancini curante. Florencia: Sansoni; 1890, p. 136.

18. Regimen Sanitatis Salerni. Caput LXXXIX. De Melancholis. Disponible en: http://www.accademiajr.it/bibvirt/ regimen.html [Consultado el 27 de febrero de 2019].

19. Africano C. Opera I, p. 288.

20. Aristóteles. Della memoria e della reminiscenza. Roma-Bari: Laterza; 1987, 2, 453a, 15-30.

21. Neckam A. De naturis rerum libri duo. Nendeln (Liechtenstein): Kraus Reprint; 1967, p. 42.

22. Aristóteles. Ética nicomáquea. Madrid: Gredos; 1985, VII, 7, 1150b, 25, p. 307. 
23. Alberti LB. Intercenales, ed. a cargo de Franco Bacchelli y Luca D’Ascia. Bolonia: Pendragon; 2003, pp. 42-3.

24. Aristóteles. Ética eudemia. Madrid: Gredos; 1985, VIII, 2, 1248a, 30, p. 542.
25. Hipócrates. Opere. Turín: UTET; 1976, pp. 567-68.

26. Ceron A. Leon Battista Alberti's Care of the Self as Medicine of the Mind, Journal of Early Modern Studies 2015; 4 (2): 9-36. 